changes using all diurnal and daily variation data. Bootstrapping was used to validate the result.

Results: Of patients included in the analysis, 13 had moderate MBDA scores and 9 had high MBDA scores at baseline. Baseline demographics were: $73 \%$ women, mean age 61.8 (SD: 12.1) years, mean MBDA score 43.9 (SD: 8.3), and mean CDAI 20.2 (SD: 17.1). No patients were on glucocorticoids. Based on the analysis of the absolute change of MBDA score in the data with daily and diurnal variation combined, the mean was 3.4 (SD: 3.8$)$, the median $(\mathrm{Q} 1, \mathrm{Q} 3)$ was $2(1,5)$, and the MID was calculated as 7 . Similar results were obtained using a bootstrap method. Minimal variability in mean MBDA scores was observed over 4 days for patients with moderate and high baseline MBDA scores (Figure 1).

Conclusions: Based upon the short term biologic variability of moderate and high MBDA scores, the MID was 7 units. An absolute change exceeding this threshold is unlikely due to diurnal and daily biological variation of the MBDA scores.

Disclosure of Interest: D. Chernoff Shareholder of: Myriad Genetics, Inc., Employee of: Crescendo Bioscience Inc., R. Bolce Shareholder of: Myriad Genetics, Inc., Employee of: Crescendo Bioscience Inc., C. Hwang Shareholder of: Myriad Genetics, Inc., Employee of: Crescendo Bioscience Inc., X. Wang Shareholder of: Myriad Genetics, Inc., Employee of: Crescendo Bioscience Inc., A. Kivitz Consultant for: Genentech, Pfizer, UCB, Janssen, J. Curtis Grant/research support from: Crescendo Bioscience Inc., Consultant for: Crescendo Bioscience Inc.

DOI: 10.1136/annrheumdis-2017-eular.5517

\section{THU0088 STRUCTURAL DAMAGE PROGRESSION IN PATIENTS TREATED WITH METHOTREXATE, BARICITINIB MONOTHERAPY OR BARICITINIB + METHOTREXATE BASED ON THEIR LEVEL OF CLINICAL RESPONSE IN THE PHASE 3 RA-BEGIN STUDY}

D. van der Heijde ${ }^{1}$, P. Durez ${ }^{2}$, G. Schett ${ }^{3}$, E. Naredo ${ }^{4}$, M. Østergaard ${ }^{5}$, G. Meszaros ${ }^{6}$, N. Bello ${ }^{6}$, I. De la Torre ${ }^{6}$, P. Lopez-Romero ${ }^{6}$, D. Schlichting ${ }^{7}$, E. Nantz ${ }^{7}$, R. Fleischmann ${ }^{8} .{ }^{1}$ Leiden University Medical Centre, Leiden, Netherlands: ${ }^{2}$ UCL-Saint Luc, Bruxelles, Belgium: ${ }^{3}$ Universitätsklinikum Erlangen, Erlangen, Germany; ${ }^{4}$ Hospital Universitario Fundación Jimenez Diaz, Madrid, Spain; ${ }^{5}$ Copenhagen Centre for Arthritis Researc, Copenhagen, Denmark; ${ }^{6}$ Eli Lilly \& Company, Madrid, Spain; ${ }^{7}$ Eli Lilly \& Company, Indianapolis; ${ }^{\circ} U$ Texas SW Medical Center, Dallas, United States

Background: Baricitinib (BARI), an oral inhibitor of Janus kinase (JAK) 1 and JAK 2 , is being developed for the treatment of rheumatoid arthritis (RA). RA-BEGIN was a phase 3 double-blind, three-arm multicentre study of BARI administered as monotherapy or in combination with methotrexate (MTX) to patients (pts) with early active RA who had no or limited treatment with DMARDs. Methotrexate (MTX) monotherapy was the active comparator.

Objectives: To evaluate the proportion of pts with structural damage progression, defined as change from baseline (CFB) greater than the smallest detectable change (SDC) in mTSS at week (wk) 52, depending on their disease state as measured by DAS28-CRP.

Methods: Pts were classified into two groups based on DAS28-CRP. Group A included pts who achieved sustained DAS28-CRP $\leq 3.2$ at weeks 16,20 and 24. Pts who did not achieve DAS28-CRP $\leq 3.2$ consecutively at weeks 16,20 and 24 and pts with missing DAS28-CRP at any of those 3 visits were included in Group B. The proportion of pts with CFB mTSS > SDC at wk 52 was estimated for each treatment arm for the two defined groups of response. The SDC in mTSS in the RA-BEGIN population at wk 52 was 1.4. Missing mTSS at wk 52 were imputed using linear extrapolation based on baseline data and the most recent radiographic data prior to the missed radiograph. No formal statistical tests were performed and comparisons are merely descriptive. All analyses were post-hoc. Results: Out of the $584 \mathrm{pts}$ of the modified-ITT population (all randomised pts who received at least 1 dose of study drug) in the RA-BEGIN study, 212 were classified in Group A: $21.4 \%$ (45/210), 42.1\% (67/159), and 46.5\% (100/215) for MTX, BARI and BARI+MTX, respectively. The odds ratios for sustained DAS28-CRP $\leq 3.2$ response (weeks 16,20 and 24 ) to BARI and BARI+MTX vs. MTX, were respectively $2.8(95 \% \mathrm{Cl} 1.7-4.4)$ and $3.3(95 \% \mathrm{Cl} 2.1-5.1)$. Pts classified in Group A maintained an adequate level of response up to wk 52 . Further, pts in Group A (sustained DAS28-CRP $\leq 3.2$ ) on either BARI + MTX or BARI, were less likely to show structural progression than patients who achieved sustained DAS28-CRP $\leq 3.2$ on MTX. Pts in Group B on MTX or BARI monotherapy were more likely to show structural progression than patients who did not achieve a sustained DAS28-CRP $\leq 3.2$ response on BARI + MTX (Figure 1).

Footnote: Group A: Patients who achieved sustained DAS28-CRP $\leq 3.2$ (NRI) at weeks 16, 20 and $24(\mathrm{~N}=212)$; Group B: Complement group

Conclusions: In patients who achieved sustained low DAS28-CRP scores, progression rates compared to MTX were reduced to a similar degree with BARI as monotherapy or in combination with MTX. Compared to MTX in patients who did not achieve sustained low DAS28-CRP scores, progression rates were reduced most markedly with combination therapy.

Disclosure of Interest: D. van der Heijde Consultant for: Abbvie, Amgen, Astellas, AstraZeneca, BMS, Boeringer Ingelheim, Celgene, Daiichi Sankyo, Eli Lilly and Company, Galapagos, Janssen, Merck, Novartis, Pfizer, Roche, Sanofi-Aventis, UCB, P. Durez: None declared, G. Schett: None declared, E. Naredo: None declared, M. Østergaard Consultant for: Abbvie, BMS, Boehringer-Ingelheim,

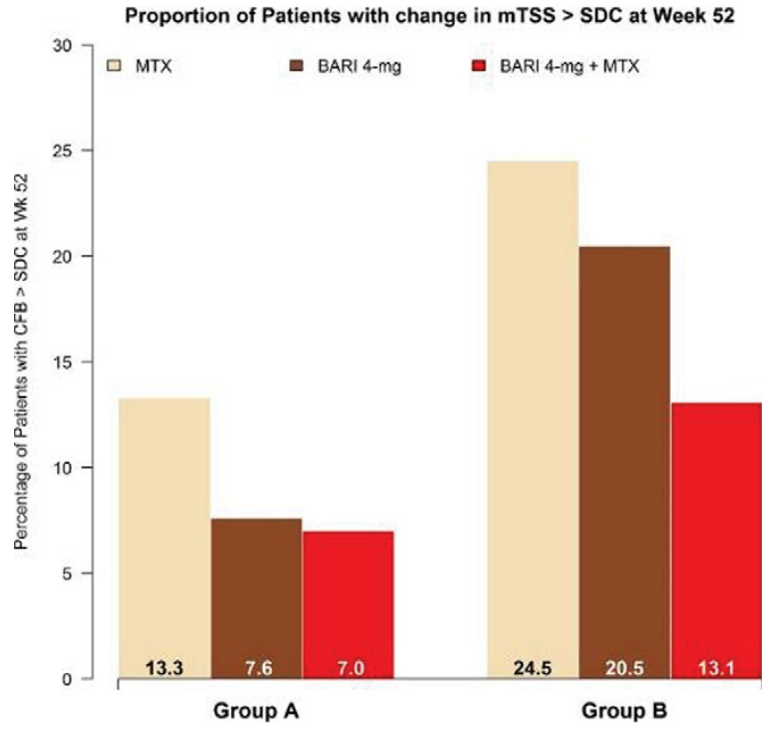

Celgene, Eli-Lilly, Centocor, GSK, Hospira, Janssen, Merck, Mundipharma, Novartis, Novo, Orion, Pfizer, Regeneron, Schering-Plough, Roche, Takeda, UCB, and Wyeth, G. Meszaros Employee of: Eli Lilly \& Company, N. Bello Employee of: Eli Lilly \& Company, I. De la Torre Employee of: Eli Lilly and Company, P. Lopez-Romero Employee of: Eli Lilly \& Company, D. Schlichting Employee of: Eli Lilly and Company, E. Nantz Employee of: Eli Lilly and Company, R. Fleischmann Consultant for: Abbvie, Amgen, Astra Zeneca, BMS, Celgene, Janssen, Eli Lilly and Company, Novartis, Roche, Sanofi-Aventis, Pfizer, UCB DOI: 10.1136/annrheumdis-2017-eular.2223

\section{THU0089 M-DAS28, DAS28 (CRP) AND RAPID3 SCORES AT BASELINE ARE GOOD PREDICTORS OF RADIOGRAPHIC DISEASE PROGRESSION AT 1 AND 2 YEARS: DATA FROM THE AMPLE TRIAL}

E. Keystone $^{1}$, H. Ahmad ${ }^{2}$, Y. Yazici ${ }^{3}$, E. Muratti ${ }^{4}$, J. Ye ${ }^{2}$, M. Bergman $^{5}$. ${ }^{1}$ University of Toronto, Toronto, Canada; ${ }^{2}$ Bristol-Myers Squibb, Princeton; ${ }^{3}$ New York University School of Medicine, New York, United States; ${ }^{4}$ Bristol-Myers Squibb, Montreal, Canada; ${ }^{5}$ Drexel University College of Medicine, Philadelphia, United States

Background: Clinicians rely on time-efficient, validated disease activity assessments to help predict disease progression accurately in patients (pts) with RA. The utility in predicting structural damage progression for the Routine Assessment of Patient Index Data 3 (RAPID3) ${ }^{1}$ is largely unknown, while that of DAS28 (CRP) ${ }^{2}$ and modified (M-)DAS28 have been previously reported. ${ }^{3}$

Objectives: This post hoc analysis examined the relationship between baseline disease activity measures and their ability to predict structural damage progression in the Phase III AMPLE (NCT00929864) trial. ${ }^{4}$

Methods: AMPLE was a randomized, investigator-blinded study in which MTXexperienced pts with active RA $\leq 5$ years received SC abatacept 125 mg weekly or adalimumab $40 \mathrm{mg}$ every 2 weeks in combination with stable-dose MTX. Logistic regression analysis was used to correlate the effect of disease activity at baseline on radiographic (X-ray) progression at Months (M) 12 and 24. Disease activity was assessed using M-DAS28, ${ }^{3}$ DAS28 (CRP), RAPID3, CDAI and SDAI. Radiographs were scored using the modified Sharp/van der Heijde scoring system; progression was defined as change from baseline in total score greater than the smallest detectable change, which was calculated as SD/square root (2) $\times 1.96$ (where SD is standard deviation of paired differences of change from baseline in total score between two readers).

Results: Logistic regression analysis was carried out for all randomized and treated pts (abatacept, $n=318$; adalimumab, $n=328$ ). For these patients, M-DAS28, DAS28 (CRP) and RAPID3 at baseline were significant predictors of radiographic progression at M12 and M24, baseline SDAI was a significant predictor at M12 but not M24 and baseline CDAI was not a significant predictor at either time point

Logistic regression model and area under ROC curves for the impact of disease activity at baseline on radiographic progression at M12 and M24 (all randomized and treated patients)

\begin{tabular}{|c|c|c|c|c|c|c|}
\hline \multirow[t]{2}{*}{ Disease activity measure } & \multicolumn{3}{|c|}{ M12 } & \multicolumn{3}{|c|}{ M24 } \\
\hline & $\mathrm{OR}(95 \% \mathrm{Cl})$ & $\mathrm{p}$ value & AUC & OR $(95 \% \mathrm{Cl})$ & $\mathrm{p}$ value & AUC \\
\hline CDAI & $1.02(1.00,1.04)$ & NS & 0.5762 & $1.01(0.99,1.03)$ & NS & 0.5416 \\
\hline SDAI & $1.02(1.00,1.04)$ & $<0.05$ & 0.5963 & $1.02(1.00,1.03)$ & NS & 0.5634 \\
\hline DAS2 & $1.47(1.15,1.90)$ & $<0.01$ & 0.6271 & $1.31(1.03,1.67)$ & $<0.05$ & 0.5911 \\
\hline RAPID3 & $1.26(1.08,1.47)$ & $<0.01$ & 0.6270 & $1.16(1.01,1.34)$ & $<0.05$ & 0.5871 \\
\hline & $1.51(1.25,1.83)$ & 0.001 & 0.6624 & $1.36(1.13,1.63)$ & $<0.01$ & 0.620 \\
\hline
\end{tabular}

$\mathrm{AUC}=$ area under the curve; $\mathrm{M}=$ month; $\mathrm{NS}=$ not statistically significant; $\mathrm{OR}=$ odds ratio; $\mathrm{ROC}$ $=$ receiver operating characteristic. 
(Table). Receiver operating characteristic curves showed that M-DAS28, DAS28 (CRP) and RAPID3 had higher predictive value (area under the curve) than CDAI or SDAI for radiographic progression at M12 and M24 (Table). There was no impact of treatment arm on predictors of radiographic outcomes.

Conclusions: In this post hoc analysis, disease activity scores at baseline according to M-DAS28, DAS28 (CRP) and RAPID3 were good predictors of radiographic progression at M12 and M24 and were more predictive than other measures of disease activity tested, with M-DAS28 demonstrating the greatest degree of prediction.

References:

[1] Yazici Y, et al. J Rheumatol 2008;35:603-9.

[2] Salaffi F, et al. BMC Musculoskelet Disord 2011;12:120.

[3] Baker JF, et al. Arthritis Rheumatol 2014;66:794-802.

[4] Schiff M, et al. Ann Rheum Dis 2014;73:86-94.

Disclosure of Interest: E. Keystone Grant/research support from: Abbott, Amgen, AstraZeneca, Bristol-Myers Squibb, F. Hoffmann-La Roche, Janssen, Lilly, Novartis, Pfizer, sanofi-aventis, UCB, Consultant for: Abbott, AstraZeneca, Biotest, Bristol-Myers Squibb, Crescendo, F. Hoffmann-La Roche, Genentech, Janssen, Lilly, Merck, Pfizer, UCB, Speakers bureau: Amgen, Abbott, AstraZeneca, BristolMyers Squibb, F. Hoffmann-La Roche, Janssen, Pfizer, Sanofi, Genzyme, UCB, H. Ahmad Shareholder of: Bristol-Myers Squibb, Employee of: Bristol-Myers Squibb, Y. Yazici Grant/research support from: Genentech, Celgene, Bristol-Myers Squibb, Consultant for: Genentech, Celgene, Bristol-Myers Squibb, E. Muratti Employee of: Bristol-Myers Squibb, J. Ye Shareholder of: Bristol-Myers Squibb, Employee of: Bristol-Myers Squibb, M. Bergman Shareholder of: Pfizer, Johnson \& Johnson, Consultant for: AbbVie, Bristol-Myers Squibb, Amgen, Celgene, Genentech, Pfizer, Janssen, Speakers bureau: Norvatis, Abbvie, Celegene

DOI: 10.1136/annrheumdis-2017-eular.1930

\section{THU0090 INFLUENCE OF AGE AT DISEASE ONSET ON CLINICAL, FUNCTIONAL, AND ULTRASONOGRAPHIC OUTCOMES IN A MONOCENTRIC EARLY RHEUMATOID ARTHRITIS COHORT}

E. Galuppi, I. Farina, C. De Giorgio, C.A. Scirè, M. Govoni. Department of Medical Sciences, UOC Rheumatology, University of Ferrara and Azienda Ospedaliero-Universitaria Sant'Anna, Ferrara, Italy

Background: Rheumatoid Arthritis (RA) onset may occur at any age and peaks in the fifth decade. Because the mean age of general population is continually increasing and since older age could impact on outcomes, late-onset RA (LORA) will probably become a relevant issue for health care system in the next future. A better characterization of LORA could help rheumatologist in the therapeutic decision-making process tailored on the individual patient.

Objectives: To investigate the relationship between age at disease onset and clinical, ultrasonographic and functional outcomes.

Methods: Early RA (ERA) patients fulfilling 2010 ACR/EULAR, with available clinical ad ultrasonographic follow-up of at least 1 year, who consecutively attended our Early Arthritis Clinic between 2009-2014, were retrospectively analyzed. Patients were pooled into 3 groups by age at RA onset: $<45$ years (young-onset RA [YORA] group 1), 45 to 60 years (intermediate-onset RA [IORA] group 2), and $>60$ years (late-onset RA [LORA] group 3). At baseline biological, functional and ultrasonographic data were recorded. The following items were compared at baseline and after 12 months from diagnosis: DAS28 $8_{\text {CRP }}$ remission rate, functional disability using the Health Assessment Questionnaire (HAQ), power doppler (PWD) score, Methotrexate (MTX) treatment, use of glucocorticoids (GCs).

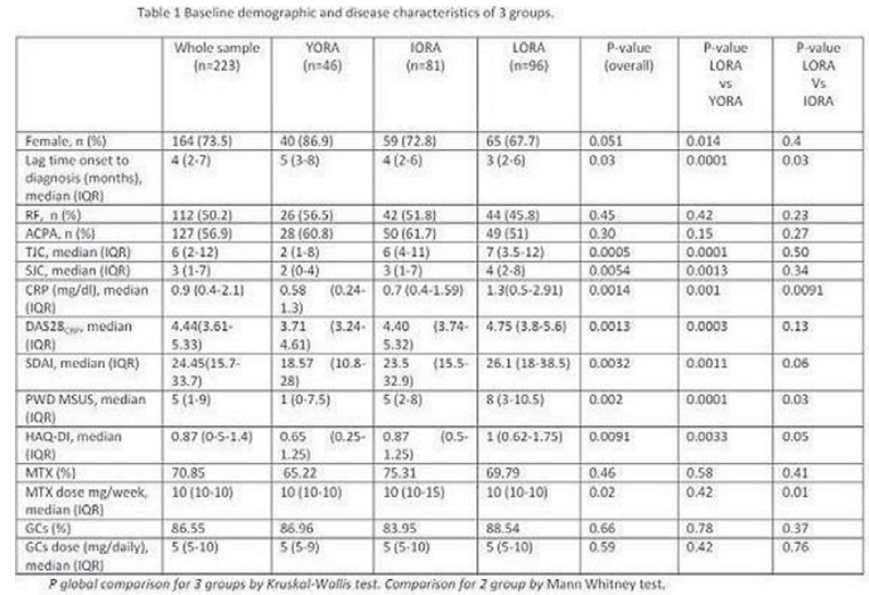

Table 2 Adjusted odds ratios (aORs) for $D A S 28$ Cw remission, PWO MSUS remission and HAQ score $<0.5$ at 1 vear follow up

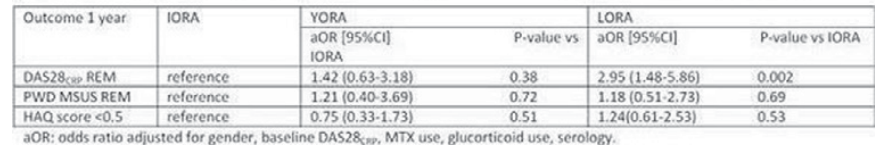

Results: The main baseline demographic and disease characteristics of the whole sample of ERA ( $n=223)$ and the 3 age groups- YORA (46), IORA (81) and LORA (96)- are summarised in Table 1. Age at RA-onset was independently associated with DAS28 $8_{\mathrm{CRP}}$ remission at 1 year (Table 2).

Conclusions: In a cohort of ERA, older age at disease onset is associated with a more active pattern disease at the beginning but with a greater probability of DAS28 ${ }_{\text {CRP }}$ remission at 1 year.

Disclosure of Interest: None declared

DOI: 10.1136/annrheumdis-2017-eular.5011

\section{THU0091 HIGH MULTI-BIOMARKER DISEASE ACTIVITY SCORE IS ASSOCIATED WITH HIGH RISK OF RADIOGRAPHIC PROGRESSION IN SIX STUDIES}

J.R. Curtis ${ }^{1}$, C.H. Brahe ${ }^{2}$, M. Ostergaard ${ }^{2}$, M.L. Hetland ${ }^{2}$, K. Hambardzumyan ${ }^{3}$, S. Saevarsdottir ${ }^{3}$, X. Wang ${ }^{4}$, E.H. Sasso ${ }^{4}$, T.W. Huizinga ${ }^{5}$. ${ }^{1}$ Univ. of Alabama at Birmingham, Birmingham, United States; ${ }^{2}$ Copenhagen Center for Arthritis Research, Copenhagen, Denmark; ${ }^{3}$ Karolinska Univ. Hospital and Karolinska Institutet, Stockholm, Sweden; ${ }^{4}$ Crescendo Bioscience Inc., South San Francisco, United States; ${ }^{5}$ Leiden Univ. Medical Center, Leiden, Netherlands

Background: The multi-biomarker disease activity (MBDA) test uses a validated algorithm with 12 serum protein biomarkers to assess disease activity in patients with RA. The MBDA score has previously been found to be a predictor of risk for radiographic progression (RP).

Objectives: To evaluate data from six cohorts to collectively establish the relationship between the MBDA score and risk for RP.

Methods: Clinical, MBDA score and radiographic data were analyzed for 6 cohorts with $\mathrm{N}>100$ : Leiden, SWEFOT Year 1, SWEFOT Year 2, OPERA Year 1, and AMPLE Year 1 (abatacept and adalimumab arms) (see Figure). Analyses used published results when available or patient-level data when not (i.e., for Leiden; and for OPERA CRP analyses). Frequency of RP over one year was determined by category of MBDA score (low, moderate [30-44], high on a scale of 1-100) at the start of the year for four cohorts and by category of MBDA score at the end of the year for AMPLE cohorts (as published). RP was defined using the threshold for change in total modified Sharp score ( $\triangle \mathrm{mTSS}$ ) specific to each study ( 2 to $>5$ TSS units). Positive and negative predictive values (PPV and NPV) were determined for each study by comparing patients with high MBDA score (>44), DAS28-(ESR/CRP) (>5.1 or $>4.09$ ) or CRP ( $>3 \mathrm{mg} / \mathrm{dL})$ vs. those in a not-high category. Relative risk (RR) for RP was determined for each study, and in a meta-analysis of the non-overlapping patient groups with MBDA scores available at the start of the year (Leiden, SWEFOT Year 1 and OPERA Year 1). Results of multivariate analyses and analyses that combined MBDA score with other risk factors for RP were summarized.

Results: The 6 study cohorts included patients receiving csDMARDs alone or with adalimumab, infliximab or abatacept. Overall rates of RP were $10-26 \%$. In each study, RP was most frequent among patients with a high vs. not-high MBDA score ( $>44$ vs. $\leq 44$ ). For high MBDA scores, NPVs were $93-97 \%$ and PPVs were $18-32 \%$, with RR values of $3.6-9.5$ ( $P=0.002$ to $<0.0001$ ) (Figure). In a meta-analysis of the Leiden, SWEFOT Year 1 and OPERA Year 1 cohorts, RR was $5.1(P<0.0001)$ for MBDA categories, and $1.4(P=0.23)$ and $1.6(P=0.01)$ for categories of DAS28-CRP or CRP, respectively. Previously published multivariate analyses in the Leiden and SWEFOT Year 1 cohorts showed that MBDA score was an independent predictor of RP compared with other predictors. In the Leiden cohort, MBDA score was the strongest predictor and high MBDA score

\begin{tabular}{|c|c|c|c|c|c|c|c|}
\hline \multicolumn{8}{|c|}{ Association between radiographic progression (RP) and high MBDA score (>44) } \\
\hline Cohort & $\mathbf{N}$ & $\begin{array}{l}\text { RP } \\
\text { cutoff }\end{array}$ & $\begin{array}{l}\text { Overall } \\
\text { \% RP }\end{array}$ & $\begin{array}{l}\text { PPV for } \\
\text { MBDA }>44\end{array}$ & $\begin{array}{l}\text { NPV for } \\
M B D A>44\end{array}$ & $\begin{array}{l}\text { Relative Risk }^{1} \\
\quad(95 \% \mathrm{Cl})\end{array}$ & P-value \\
\hline Leiden & 163 & $>5.0$ & $17 \%$ & $31 \%$ & $93 \%$ & $\begin{array}{c}4.3 \\
(1.9,9.5)\end{array}$ & $<0.0001$ \\
\hline $\begin{array}{l}\text { OPERA } \\
\text { Year } 1\end{array}$ & 164 & $\geq 2.0$ & $26 \%$ & $31 \%$ & $97 \%$ & $\begin{array}{c}9.5 \\
(1.4,66.3)\end{array}$ & 0.0009 \\
\hline $\begin{array}{l}\text { SWEFOT } \\
\text { Year } 1\end{array}$ & 235 & $>5.0$ & $18 \%$ & $21 \%$ & $97 \%$ & $\begin{array}{c}7.1 \\
(1.0,49.9)\end{array}$ & 0.008 \\
\hline \multicolumn{6}{|c|}{ Meta-analysis (LEIDEN + OPERA Year $1+$ SWEFOT Year 1 ) } & $\begin{array}{c}5.1^{3} \\
(2.5,10.1)\end{array}$ & $<0.0001$ \\
\hline $\begin{array}{l}\text { SWEFOT } \\
\text { Year } 2\end{array}$ & 133 & $>5.0$ & $13 \%$ & $32 \%$ & $95 \%$ & $\begin{array}{c}6.2 \\
(2.4,16.5)\end{array}$ & 0.0001 \\
\hline $\begin{array}{l}\text { AMPLE } \\
\text { Year } 1 \text { (Aba) }\end{array}$ & 181 & $>2.2^{4}$ & $10 \%$ & $18 \%$ & $96 \%$ & $\begin{array}{c}4.5 \\
(1.6,13.1)\end{array}$ & 0.003 \\
\hline $\begin{array}{l}\text { AMPLE } \\
\text { Year } 1 \text { (Ada) }\end{array}$ & 186 & $>2.2^{4}$ & $11 \%$ & $24 \%$ & $93 \%$ & $\begin{array}{c}3.6 \\
(1.6,8.1)\end{array}$ & 0.002 \\
\hline
\end{tabular}

PPV, positive predictive value; NPV, negative predictive value. 1. Relative risk $=\mathrm{PPV} /(1-\mathrm{NPV}) .2$. Random-effect model used for meta-analysis. 3.Aggregated relative risk. 4. $\triangle T S S$ cutoff for RP was defined in Fleischmann et al (Arthritis Rheumatol 2016;68:2083-9) as >smallest detectable change (SDC), however no value was specified; SOC for AMPLE was specified as 2.8 and 2.2 in prior AMPLE publications (Weinblatt 2013; Schiff 2014).

Treatments; reference; data source:

LEIDEN (cSDMARDs); Li et al. Rheumatology (Oxford). 2013;55:357-66; Unpublished patient-level data only. OPERA (MTX+placebo-adalimumab+IA corticosteroids/MTX+adalimumab+IA corticosteroids); Brahe et al. Arthritis Rheumatol. ACR 2016 Abstract 2520; Published data and unpublished patient-level data for analysis of CRP categories.

SWEFOT Year 1 (MTX/triple therapy/MTX+infliximab); Hambardzumyan K, et al. Ann Rheum Dis. 2015;74:1102-9; Published data only.

2015;74:1102-9; Published data only.
SWEFOT Year 2 (triple therapy/MTX+infliximab); Hambardzumyan K et al, RMD Open. $2016 \mathrm{Mar}$ SWEFOT Year 2 (triple therapy/MTX

1;2(1):e000197, Published data only.

AMPLE Year 1 (abatacept and adalimumab arms, analyzed separately); Fleischmann et al. Arthritis Rheumatol 2016;68:2083-9, Curtis et al. Arthritis Rheumatol. 2016 Nov 3. doi: 10.1002/art.39981 and *Fleischmann et al
Arthritis Rheumatol. 2016 Dec 19. DOI: 10.1002/art.40021; Published data only, from Fleischmann et al(*). 